\title{
Uma proposta de vigilância em saúde do trabalhador com a ótica de gênero
}

\author{
A proposal for worker's health surveillance \\ with a gender perspective
}

Jussara Brito 1

1 Centro de Estudos da Saúde do Trabalhador e Ecologia Humana, Escola Nacional de Saúde Pública Fundação Oswaldo Cruz. Rua Leopoldo Bulhões 1480, Rio de Janeiro, $R J$ 21041-210, Brasil.

\begin{abstract}
This paper deals with differences and inequalities. The current workers' health surveillance model is discussed, pointing to the need for a gender perspective in this area. The article maintains that certain classical notions should be reviewed and that risk maps can be more useful if they are capable of identifying exposure according to gender, thus enhancing the different kinds of division of labor under which they operate. Women workers' proposals are placed alongside sociological analyses in terms of the interface between production and reproduction and the debate over the gender perspective in the health-disease process. The paper concludes with an attempt to establish a new approach to workers' health surveillance, highlighting the centralness of work and the inter-subjectiveness of determining the relationship between production and health.
\end{abstract}

Key words Worker's Health; Gender; Women's Health; Health Surveillance

Resumo Esse texto trata de diferenças e desigualdades. Discute-se o atual modelo de vigilância sanitária em saúde do trabalhador, apontando a necessidade de incorporação de um olhar de gênero nessa prática. Mostra-se que certas noções clássicas devem ser revistas e que os mapas de riscos podem ser mais úteis se forem capazes de indicar as distribuições das exposições segundo o gênero, evidenciando as modalidades de divisão do trabalho que são operadas. As propostas das trabalhadoras são colocadas ao lado das análises advindas da sociologia, no que se refere à articulação entre produção e reprodução, e do debate sobre a perspectiva de gênero na apreensão do processo saúde-doença. Ao final do texto, procura-se caminhar no sentido de uma nova forma de pensar a vigilância em saúde do trabalhador, ressaltando a centralidade do trabalho e da intersubjetividade na determinação da relação produção/saúde.

Palavras-chave Saúde do Trabalhador; Gênero; Saúde da Mulher; Vigilância em Saúde 


\section{Introdução}

Nas indústrias, as mulheres estão nos pequenos estabelecimentos, atomizadas nos postos "menos qualificados", muitas vezes contratadas por empreiteiras (as chamadas "agências"), sendo estimuladas à competição e à manutenção de um ritmo extenuante de trabalho. Realizam atividades múltiplas, aparentemente simples e pseudo designadas como "auxiliar de produção" ou "auxiliar de embalagem" ou outros nomes ainda mais bizarros e desqualificadores. São obrigadas a enquadrar-se no padrão de feminilidade, isto é, a desenvolverem qualidades como habilidade manual, disponibilidade e paciência, sem receberem treinamento para isso, pois as tarefas que devem executar são "naturalmente" prescritas. Os espaços físicos onde exercem suas funções são diferenciados e concebidos com a perspectiva do isolamento e da manutenção da hierarquia de gênero. Ou estão situados num local esquecido da planta industrial, um lugar de acesso mais difícil, ou ficam longe de banheiros ou instalados em pontos estratégicos para o exercício da disciplina e do controle. A comunicação com os colegas é normalmente proibida e, além disso, são vítimas de outras modalidades de violência, sejam verbais ou físicas. Nos espaços que lhes são reservados no processo produtivo, ficam em contato direto e manual com substâncias químicas. Nas indústrias farmacêuticas, de plásticos e de cosméticos, por exemplo, onde o número de operárias é significativo, os sintomas alérgicos indicam suas condições precárias de trabalho (Brito, 1996).

Nos demais setores da produção, no serviço, no comércio e na agricultura, algumas características gerais do trabalho feminino persistem. A noção de valor do trabalho baseada nas relações de gênero implica salários inferiores, qualquer que seja a configuração da divisão sexual do trabalho (Kergoat, 1995). A hierarquia de gênero manifesta-se na organização do trabalho, com acento nas formas coercitivas de gestão. As desigualdades expressam-se inclusive nos direitos diferenciados das trabalhadoras e dos trabalhadores, uma vez que as funções desempenhadas pelos homens e pelas mulheres são distintas, com exigências e riscos mais ou menos demonstráveis e mensuráveis. A legislação, se é restritiva para caracterização de insalubridade/penosidade/periculosidade do conjunto dos ambientes de trabalho, é ainda mais limitada para apontar a inadequação das condições de trabalho das mulheres, não havendo, entre outros, padrões que limitem a repetitividade e a cadência elevada, que carac- terizam em geral as suas atividades (Volkoff, 1985). Assim, justificam-se adicionais salariais e outras vantagens (como, por exemplo, pausas) para trabalhadores que são vinculados aos departamentos cuja mão de obra é majoritariamente masculina, na medida que os riscos presentes nesses ambientes são mais facilmente comprováveis. Acrescentam-se os efeitos não muito claros sobre a saúde do trabalho a domicílio e de outros tipos de trabalho informal e precário que são exercidos por um grande número de mulheres.

É necessário pensar em estratégias para intervir nos processos que afetam particularmente a saúde da mulher trabalhadora, com seus riscos invisíveis. É preciso que tenhamos clareza de que o questionamento da divisão sexual do trabalho interessa a todos os trabalhadores e não ao capital, na sua lógica de apropriação da força de trabalho e de lucro. A incorporação de um olhar sexuado nas ações de vigilância sanitária representa uma possibilidade para se romper com o círculo vicioso em que nos encontramos e que nos leva à aceitação das formas de opressão dirigidas às trabalhadoras. Esse olhar nos remete a uma crítica profunda das formas de organização do trabalho e de exploração do feminino e do masculino, impondo-nos uma redefinição da prática de vigilância em saúde do trabalhador.

Nesse sentido, cabe discutir os conceitos que orientam essas práticas e refletir sobre a necessidade de eleger o problema das desigualdades como critério fundamental de análise. A noção clássica de risco, amplamente utilizada como referência na observação dos processos de trabalho, configura-se como uma armadilha, pois não privilegia fatores vinculados às relações de gênero. Portanto, é fundamental rever essa noção, incorporando categorias de risco indicativas das experiências das mulheres trabalhadoras e evidenciando os fenômenos coletivos aos quais está sujeito especificamente esse grupo.

Espera-se também que o ponto de vista de gênero possa contribuir com o aprimoramento da elaboração de mapas de riscos. Concebidos como um instrumento de análise das situações de risco existentes nos ambientes de trabalho, uma das limitações de sua forma mais corrente é a abstração das características dos indivíduos que desempenham as atividades. Dessa maneira, os mapas de riscos não mostram como ocorre a divisão sexual do trabalho - assim como outras modalidades de divisão do trabalho entre grupos diferentes - e, conseqüentemente, não colocam em foco as distribuições das exposições segundo o gênero. Contudo, a divi- 
são social do trabalho é fundada nas diferenças e produz desigualdades.

A articulação entre produção e reprodução e a extensibilidade das relações de classe e de sexo têm sido objeto de debate na sociologia (Kergoat, 1984; Combes \& Haicault, 1984; Hirata, 1994; Souza-Lobo, 1991). Os autores chamam a atenção para a assimetria das experiências femininas e masculinas. Por outro lado, as mulheres trabalhadoras têm manifestado suas inquietações, denunciando a opressão no mundo público e privado e trazendo novos temas para o sindicalismo. Assim, propõem a adoção de políticas sindicais sobre o assédio sexual e a sua inclusão como um tema de saúde. Propõem ainda que a questão da violência contra as mulheres, doméstica ou não, seja discutida no sindicalismo, tendo em vista a implementação de programas educacionais (CIOSL, 1994). A invisibilidade dos problemas de condições de trabalho e saúde das mulheres levou à redação, no I Congresso Internacional "Mulher, Trabalho, Saúde”, realizado em abril de 1996, de um documento consensual, que enfatiza a necessidade de que a perspectiva de gênero seja introduzida na investigação e na docência, objetivando a promoção de saúde e assistência sanitária com esse viés (CAPS, 1996).

Como podemos ver, o viés de gênero tem introduzido questões importantes para a apreensão do processo saúde-doença e nos estudos da relação trabalho e saúde. Para Breilh (1993), a epidemiologia de gênero não se reduz à investigação da morbidade e mortalidade que afetam a mulher, nem aos contrastes estatísticos entre sexos, nem à busca de nexos entre patologias femininas e fatores sociais específicos, por mais importantes que sejam essas análises. As investigações nesse campo, para o autor, devem explicar como as condições e relações de gênero intervêm no processo de determinação de saúde-doença, levando em conta que essas relações se modificam historicamente e que têm expressões distintas nos diversos grupos humanos. A pesquisadora Mergler (1995), pensando "gênero" como determinante das condições de trabalho - e não uma simples forma de classificar os trabalhadores critica, por sua vez, o modelo estatístico epidemiológico por tratar "sexo" como uma variável independente, ou seja, por não considerar que no gênero estão embutidas as construções sociais que levam às definições das situações de trabalho e dos modos de vida.

Diante dessas questões, pode-se afirmar o seguinte: a vigilância em saúde do trabalhador deve estar centrada na atenção de todas as formas de desigualdade que são engendradas pe- la divisão do trabalho, desconstruindo aquilo que parece ser natural. Intervindo nos processos de trabalho com um olhar que contemple as diferenças de gênero, isto é, com uma visão mais completa do mundo do trabalho, é provável que problemas ainda mais graves emirjam. É certo que o atual modelo de intervenção não é capaz de enfrentar as desigualdades que são produzidas pelas relações sociais (de classe e gênero) e que estão presentes nos processos de trabalho. Em conseqüência, não são priorizados problemas que resultam diretamente da divisão sexual do trabalho e da hierarquia de gênero.

Para que se concretize essa proposição é preciso não apenas estar atento aos riscos que são gerados pelos instrumentos e objetos de trabalho, mas também aos tratamentos diferenciados. Além disso, é necessário que as ações em curso nos Programas de Saúde do Trabalhador, bem como suas comissões específicas sejam acompanhadas por trabalhadores(as) ou técnicos(as) sensíveis à divisão sexual do trabalho e às relações de gênero. Algumas perguntas podem orientar essa nova prática. Como se caracterizam as localizações funcionais, em relação ao acesso a banheiros, copas e outros compartimentos coletivos? Há algum grupo sujeito à interdição de falar, seja por causa do ritmo de trabalho ou mesmo devido a normas explicitamente impostas? Estão os(as) trabalhadores(as) expostos a um conjunto de riscos e exigências não muito visíveis em função das atividades reais desempenhadas? As formas de controle da produção e da mão de obra são iguais para todos os setores? Todos os(as) trabalhadores(as) têm os mesmos direitos? Há evidências de abuso de poder ou de que trabalhadores(as) sejam ameaçados(as) ou agredidos(as) verbalmente ou fisicamente?

Essa nova forma de pensar a vigilância em saúde do trabalhador está em sintonia com a percepção de que a relação trabalho-saúde é complexa e múltipla. Nesse sentido, a questão das diferenças deve ser compreendida como um ponto de vista indispensável para que a abordagem latino-americana de estudos da saúde do trabalhador seja enriquecida conceitual e metodologicamente, reafirmando a centralidade da categoria trabalho, na sua acepção ampliada, mas também assumindo a centralidade das relações intersubjetivas (Hirata, 1993), que foi apontada dentro da sociologia e pelo movimento de mulheres. 


\section{Referências}

BREILH, J., 1993. Genero, Poder y Salud. Ibarra: Ediciones CEAS-UNT.

BRITO, J., 1996. Trabalho e Saúde nas Indústrias de Processos Químicos: a Experiência das Trabalhadoras. Tese de Doutorado, Rio de Janeiro: Escola Nacional de Saúde Pública, Fundação Oswaldo Cruz.

CAPS (Centro de Análisis y Programas Sanitarios), 1996. Documento de Consenso. Congresso Internacional "Women, Work, Health". Barcelona.

CIOSL (Confederação Internacional das Organizações Sindicais Livres), 1994. Con la igualdad cambiara el mundo: la vision sindical. Transformar la vision en realidad. VI Conferencia Mundial para la Mujer. Haya.

COMBES, D. \& HAICAULT, M., 1984. Production et reproduction, rapports sociaux de sexes et de classes. In: Le sexe du Travail (Barrère-Maurisson; Battagliola; Becalli; Borzeix; Chabaud; Chaudron; Combes; Daune-Richard; Devreux; Ferrand; Fougeyrollas-Schwebel; Gitahy; Haicault; HakikiTalahite; Hirata; Humphrey; Kartchevsky-Bulport; Kergoat; Langevin; Laufer; Le Doaré; Maruani; Moyses; Pacifico; Ronci; Souza-Lobo; eds.), pp. 155-174. Grenoble: PUG.

HIRATA, H., 1993. Division sexuelle du travail et internationale du travail. Futur Antérieur, 16:27-40.
HIRATA, H., 1994. Rapports Sociaux de Sexe et Division du Travail: Contribution à la Discussion sur le Concept de Travail. Paris. (mimeo.)

KERGOAT, D., 1984. Plaidoyer pour une sociologie des rapports sociaux. De l'analyse critique des catégories dominantes à la mise en place d'une nouvelle conceptualisation. In: Le Sexe du Travail (Barrère-Maurisson; Battagliola; Becalli; Borzeix; Chabaud; Chaudron; Combes; Daune-Richard; Devreux; Ferrand; Fougeyrollas-Schwebel; Gitahy; Haicault; Hakiki-Talahite; Hirata; Humphrey; Kartchevsky-Bulport; Kergoat; Langevin; Laufer; Le Doaré; Maruani; Moyses; Pacifico; Ronci; Souza-Lobo; eds.), pp. 207-220. Grenoble: PUG.

KERGOAT, D., 1995. De la division sexuelle du travail et des conséquences sue les conditions de travail. In: Invisible: la Santé des Travailleuses. (K. Messing; B. Neis \& L. Dumais, orgs.), pp. 252-261. Charlottetown: Gynergy Books.

MERGLER, D., 1995. Adjusting for gender differences in occupational health studies. In: Invisible: la Santé des Travailleuses. (K. Messing; B. Neis \& L. Dumais, org.), pp. 236-251. Charlottetown: Gynergy Books.

SOUZA-LOBO, E., 1991. A Classe Operária Tem Dois Sexos. São Paulo: Brasiliense.

VOLKOFF, S., 1985. Ouvrières: le degré zero de l'autonomie. Les Temps Modernes, janvier:5-10. 